Association for Information Systems AIS Electronic Library (AISeL)

8-16-1996

\title{
Countering the Anchoring and Adjustment Bias with Decision Support Systems
}

Joey F. George

Information \& Management Sciences Department, College of Business, Flordia State University, jgeorge@cob.fsu.edu

Kevin Duffy

Information \& Management Sciences Department, College of Business, Flordia State University

Follow this and additional works at: http://aisel.aisnet.org/amcis 1996

\section{Recommended Citation}

George, Joey F. and Duffy, Kevin, "Countering the Anchoring and Adjustment Bias with Decision Support Systems" (1996). AMCIS 1996 Proceedings. 102.

http://aisel.aisnet.org/amcis1996/102

This material is brought to you by the Americas Conference on Information Systems (AMCIS) at AIS Electronic Library (AISeL). It has been accepted for inclusion in AMCIS 1996 Proceedings by an authorized administrator of AIS Electronic Library (AISeL). For more information, please contact elibrary@aisnet.org. 


\title{
Countering the Anchoring and Adjustment Bias with Decision Support Systems
}

\author{
Joey F. George \\ Kevin Duffy \\ Information \& Management Sciences Department \\ College of Business \\ Florida State University \\ Tallahassee, FL 32306-1042 \\ phone: (904) 644-8213 \\ fax: (904) 644-8225 \\ e-mail: jgeorge@cob.fsu.edu
}

\begin{abstract}
Decision support systems have long been developed to supplement limited human information processing capabilities (Sprague, 1980; Alter, 1980). For example, several systems have been developed that support specific decision-making strategies, such as multi-criteria decision making. Human decision making, however, has been found to suffer from limitations other than limited information processing capabilities. Psychologists, such as Tversky and Kahneman (1974), have worked during the past several decades to uncover systematic biases in human decision making processes. Many of these biases, such as framing, representativeness, and availability, have become well-known in the literature (e.g., Hogarth, 1987). Yet few decision support systems seem to have been developed to specifically counter these well-known decision making biases. In the cases where such DSS have been built (Todd \& Benbasat, 1991), decision making behavior has been successfully altered through interaction with the system.
\end{abstract}

One particularly interesting decision making bias is anchoring and adjustment, described by Tversky and Kahneman (1974: 1128) as follows:

In many situations, people make estimates by starting from an initial value that is adjusted to yield the final answer. The initial value, or starting point, may be suggested by the formulation of the problem, or it may be the result of a particular computation. In either case, adjustments are typically insufficient. That is, different starting points yield different estimates, which are biased toward the initial values.

To demonstrate the anchoring and adjustment effect, Tversky and Kahneman asked subjects to estimate the percentage of United Nations member states that were African nations. The researchers spun a wheel of fortune, with numbers ranging from 0 to 100, in the presence of the subjects. Subjects were first asked to determine if the random value from the wheel was too high or too low of an estimate, and then to actually estimate the percentage of African membership at the U.N. The random, arbitrary numbers had an effect on subjects' responses. For example, those who received 10 as the value guessed 25\% African membership, while those receiving 65 guessed $45 \%$.

The robustness of the anchoring and adjustment effect outside the laboratory was demonstrated by Northcraft and Neale (1987) in an experiment involving the estimation of the value of a house for sale. All subjects were given a tour of the house in question and identical information about it, except for the listing price. The researchers found that the listing price significantly biased the estimates given by the subjects, whether the price was $4 \%$ or $12 \%$ above or below the house's appraised value, and whether or not the subjects were students or experienced real estate agents.

Block and Harper (1991) found that the anchoring and adjustment effect remained strong, even when subjects were warned by the researchers that they could be too overconfident in the accuracy of their estimates. Warnings decreased the anchoring and adjustment effect somewhat but did not eliminate it. 
Given some evidence of the ability of decision support systems to influence decision making behavior in a direction away from bias (Todd \& Benbasat, 1991), we wanted to investigate the possibility of mitigating the anchoring and adjustment effect through the use of a decision support system. Our research question is whether and to what extent computerized decision support can lessen the anchoring and adjustment effect in subjects asked to estimate a particular value. To investigate this question, we have developed a DSS, using Microsoft Access 2.0 and Microsoft Visual Basic 3.0, which is designed to help users estimate the value of a house, similar to the task undertaken in Northcraft and Neale (1987). Within the Northcraft and Neale study, subjects were taken to the house, permitted to examine the property, and then asked to supply information responses. In our study, comparable information has been collected concerning the house. We are sharing this same information with our subjects, except that we are doing so electronically, rather than transporting them (physically) to the house. Subjects will be subjected to either a control condition, in which no asking price is made available, or to one of three treatments: 1 ) an asking price $12 \%$ above the appraised value is provided (twelve percent represents the extreme range used by Northcraft and Neale); 2) the asking price is provided, and subjects are warned if their initial suggested value is too close to the asking price; or 3) the asking price is provided, and if the subject's initial suggested value is too close to the asking price, the system suggests another value.

Even though Block and Harper (1991) found warnings had limited effects, they did find that warnings worked to reduce bias somewhat. They presented their warnings at the beginning of the experimental treatment, as part of the materials given to subjects. We will allow subjects to first generate a value, receive a warning if the value is too close to the appraised value, and then generate a replacement value if they want. We believe the opportunity to generate a second value after the warning will increase the strength and effect of the warning in decreasing bias. We further expect that a stronger intervention, where subjects are presented with a system generated value as a replacement to their own initial value, will have the effect of decreasing bias even more. We expect many subjects to accept the system-generated value outright, while others will adopt the system-generated value as a new anchor and adjust accordingly. Overall, then, we expect the control condition to have the most variance in their estimated value of the house, followed in decreasing order of variance by Treatments 1,2 and 3.

\section{Research Design}

All of the necessary information about a house for sale in the Tallahassee area has been obtained through the assistance of a realtor. This information is the same as that used in the Northcraft and Neale (1987) experiment:

* standard Multiple Listing Service (MLS) listing sheet for the property;

* MLS summary data for the city and the immediate neighborhood for the preceding six months;

* comparative information about other property in the same neighborhood;

* standard MLS information for other properties for sale in the same neighborhood.

This information has been used to populate a DSS designed in Microsoft Access 2.0 and Microsoft Visual Basic 3.0. Initial screens gather demographic information about the subject. After completing these forms, the subject arrives at the "house form" (see Figure 1), where subjects can use radio buttons to determine the information they want to see. Digitized photos of the house and yard are also available to subjects.

After spending as much time as they want perusing this information, subjects choose the final options, to proceed with their work. At this screen, subjects are asked to provide four pieces of information:

* an appraised value for the house; 
* a fair advertising price for the house;

* a listing price;

* an amount reflecting the lowest offer they would accept as seller of the house.

Subjects in the treatments can also access the owner's asking price. In the warning treatment, warnings screens will appear after each value entered if the value is within a range extending $12 \%$ above and $12 \%$ below the asking price. In the system-generated-value treatment, the system will offer its alternative value when the input value falls within the same $+/-12 \%$ range. In each case, subjects will have the opportunity to go with the value they already entered or to generate another value.

We are currently in the process of organizing a pilot study to test the system and the interventions. Once completed, we will begin to recruit undergraduate students for the study from the College of Business. We initially plan to run 25 subjects per treatment and in the control, for a total of 100 subjects. Subjects will participate 10 at a time in 10 sessions to be run in our decision support laboratory. The laboratory has stations for 20 participants, so each subject will be separated from his or her neighbor by an empty station, to minimize the effects of subjects influencing each other's work.

\section{References}

(Available upon request from second author.) 


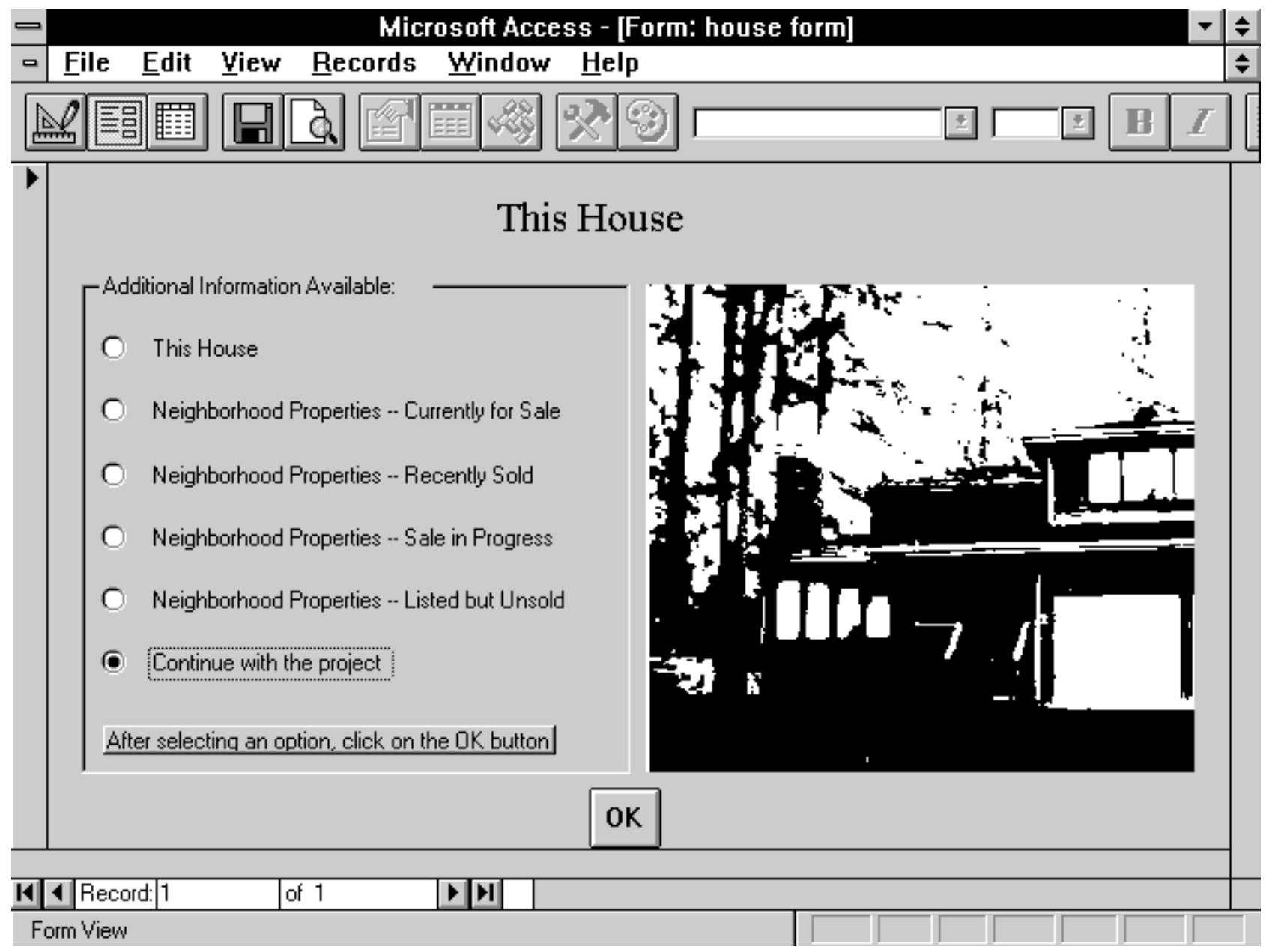

Figure 1: House Information Screen 